\title{
Multi-decadal changes in two co-occurring ophiuroid populations
}

\author{
A. Blanchet-Aurigny ${ }^{1, *}$, S. F. Dubois ${ }^{1}$, C. Hily ${ }^{2}$, S. Rochette ${ }^{3}$, E. Le Goaster ${ }^{1,2}$, \\ M. Guillou²
} ${ }^{1}$ IFREMER, Laboratoire d'Ecologie Benthique, Département Océanographie et Dynamique des Ecosystèmes,
Centre de Bretagne, BP70, 29280 Plouzané, France

${ }^{2}$ Institut Universitaire Européen de la Mer, Université de Bretagne Occidentale, LEMAR UMR CNRS IRD 6539, Place Nicolas Copernic, 29280 Plouzané, France

${ }^{3}$ IFREMER, Laboratoire Applications Géomatiques, Département Océanographie et Dynamique des Ecosystèmes, Centre de Bretagne, BP70, 29280 Plouzané, France

\begin{abstract}
Mixed beds of Ophiocomina nigra and Ophiothrix fragilis (Echinodermata, Ophiuroidea) are usually predominated by $O$. fragilis and are reported to be stable over time. The Bay of Brest (Brittany, France) is a highly productive ecosystem where both species co-occur in the main central part. Using a geostatistical approach, we tested for changes in O. nigra and O. fragilis density and total biomass patterns between 1987 and 2011. Our results highlighted an increase in $O$. nigra population size and the induction of a spatial shift of the co-occurring $O$. fragilis. O. nigra increased $\sim 5$ times in density and covered almost all the study area, while its density-dependent biomass increased $\sim 3$ times (22 t km${ }^{-2}$, ash-free dry mass) between 1987 and 2011. Overall, the O. fragilis population decreased in density by $\sim 30 \%$, but its total biomass did not change over time. The current distribution pattern revealed a clear spatial exclusion of $O$. fragilis from the central part of the study area toward the southern part, overlapping beds of dead slipper limpet Crepidula fornicata, which were formerly considered to be the dominant suspension-feeder species in the bay. The success of $O$. nigra colonization is linked to its biological and functional traits, as well as deep changes in food supply over the studied period. Ecological consequences of such a large change in the benthic compartment of the bay are explored in the light of associated changes in environmental patterns.
\end{abstract}

KEY WORDS: Echinoderm · Ophiocomina nigra $\cdot$ Ophiothrix fragilis $\cdot$ Food supply $\cdot$ Kriging method $\cdot$ Suspension-feeder

\section{INTRODUCTION}

Echinoderms are reported in many systems to play key structural and functional roles; under a complex set of environmental factors, echinoderms species exhibit high population density fluctuations also called 'outbreak' or 'die-off' events in coastal and deep ecosystems (Uthicke et al. 2009). Indeed, occasional outbreaks are a feature of some echinoid (Hughes 1994) and asteroid populations (Guillou
1996, Seymour \& Bradbury 1999). Conspicuous echinoderm outbreaks were reported for the sea star Acanthaster planci in the coral reefs (Houk \& Raubani 2010) and for the green sea urchin Strongylocentrotus droebachiensis in kelp beds (Wharton \& Mann 1981), as well as numerous other sea urchin species (Andrew \& Underwood 1992, Valentine \& Edgar 2010). However, little information has been published concerning brittle star (ophiuroid) outbreaks. Few studies report sharp increases in Ophiura 
albida (Neumann et al. 2009), Amphiura filiformis, and $A$. chiajei populations in temperate shallow habitat of the North Sea and northeast (NE) Atlantic, as well as in the 2 deep-sea ophiuroids Ophiocten hastatum, in NE Atlantic, and Ophiura bathybia, in the NE Pacific (as reviewed by Uthicke et al. 2009). In European coastal shallow waters, ophiuroids often occur in soft bottom benthic assemblages, accounting for most of the benthic biomass from heterogeneous coarse sediments (Dauvin \& Ruellet 2008), to muddy communities (Goransson 2002) where they are playing key functions in the coupling of benthic-pelagic systems (Allen 1998). A few ophiuroid species classically structure those communities, namely Amphiura filiformis (Müller) (Bowmer 1982, Bourgoin \& Guillou 1988) and Acrocnida brachiata (Montagu) (Thiébaut et al. 1997) as well as the 2 common co-occurring brittle star species, Ophiocomina nigra (Abildgaard) and Ophiothrix fragilis (Abildgaard). The latter has been widely reported and surveyed in the NE Atlantic region where large beds have been reported, with densities reaching $>1500$ ind. $\mathrm{m}^{-2}$ (e.g. Muths et al. 2010 and references therein). Similarly, O. nigra distribution covers a broad range of sedimentary features, but its densities rarely exceed those of $O$. fragilis even in mono-specific beds.

Situated in an ecotone between the English Channel and the Atlantic Ocean (Bay of Biscay), the Bay of Brest (Brittany) hosts populations of both Ophiocomina nigra and Ophiothrix fragilis. As in many systems with a high primary production, benthic assemblages are dominated by suspension-feeders, in general and especially $O$. fragilis, colonizing a large area in this bay. Distribution of $O$. fragilis in the main part of the bay was monitored early in the 1990s, leading to the conclusion that ecological conditions for this species were optimal (Hily 1991). We used the Bay of Brest as a geographical model to test possible expansion or regression mechanisms of the main ophiuroid species, namely $O$. fragilis and the co-occurring $O$. nigra. Using $O$. fragilis published data (Hily 1991) and unpublished O. nigra data from the same survey, we aim at investigating changes in density and biomass between 2 distant time periods for ophiuroid populations. Our study shall provide new insights into long-term echinoderm population dynamics and the potential consequences for associated benthic communities and control of phytoplankton biomass. Investigating the same area after a long period of time with similar protocols has proven to be successful for monitoring and detecting long-term changes in benthic assemblages (Reise 1982, Reise \& Schubert 1987, Hily et al. 2008). Differences between past and current data were explored according to $O$. nigra and $O$. fragilis biological traits as well as changes in environmental parameters.

\section{MATERIALS AND METHODS}

\section{Study area}

The Bay of Brest is a shallow semi-enclosed marine coastal system of $\sim 180 \mathrm{~km}^{2}$ connected to the Atlantic Ocean by a narrow opening of $1.8 \mathrm{~km}$ width (Fig. 1). This bay is a macrotidal system (tidal amplitude: max. $8 \mathrm{~m}$; tidal current: $\max .2 .6 \mathrm{~m} \mathrm{~s}^{-1}$ ) that receives anthropogenic nutrient inputs from rivers which are promoted by high hydrodynamic mixing (Le Pape et al. 1996). This site is characterized by a high diversity in sedimentary features: estuaries and muddy banks, slopes and channels, heterogeneous sediments and rocky area. Biogenic components such as maerl Lithothamnium corralioides beds and accumulations of the gastropod Crepidula fornicata cover the sediment and create favorable supports and refuge for many benthic species (Hily 1989). Since its introduction in 1950, the slimper limpet C. fornicata expanded from $45 \mathrm{~km}^{2}$ in 1978 (southern basin) (Coum 1979) to $90 \mathrm{~km}^{2}$ in 1995 (southern and central basins) (Fig. 1; Chauvaud et al. 1998) and constitutes the main benthic suspension-feeder in the bay (Chauvaud et al. 1998).

\section{Sampling methods}

In February 2011, a video survey was conducted in the main central part of the Bay of Brest, using the same video protocol and the same sampling points as Hily (1991) in 1987 (Fig. 1). A total of 72 video profiles were recorded using an underwater HD video camera (Sony HD CX6) mounted on a weighted structure with a $0.05 \mathrm{~m}^{2}$ metal frame welded in its lower part, so that the camera would focus on both the frame and the sediment surface. Two green laser pointers (S2000BLG Subsea) were mounted on each side of the camera and calibrated to provide an accurate scale (1 mm precision) on each picture or video. Instantaneous pictures were taken each time the frame hit the bottom. Subsequent to that first picture, the structure was lifted for $5 \mathrm{~s}$ and dropped for the next picture, while the research vessel was in neutral but still moving with the current. For each of the 72 stations, 20 pictures were taken along a transect of 


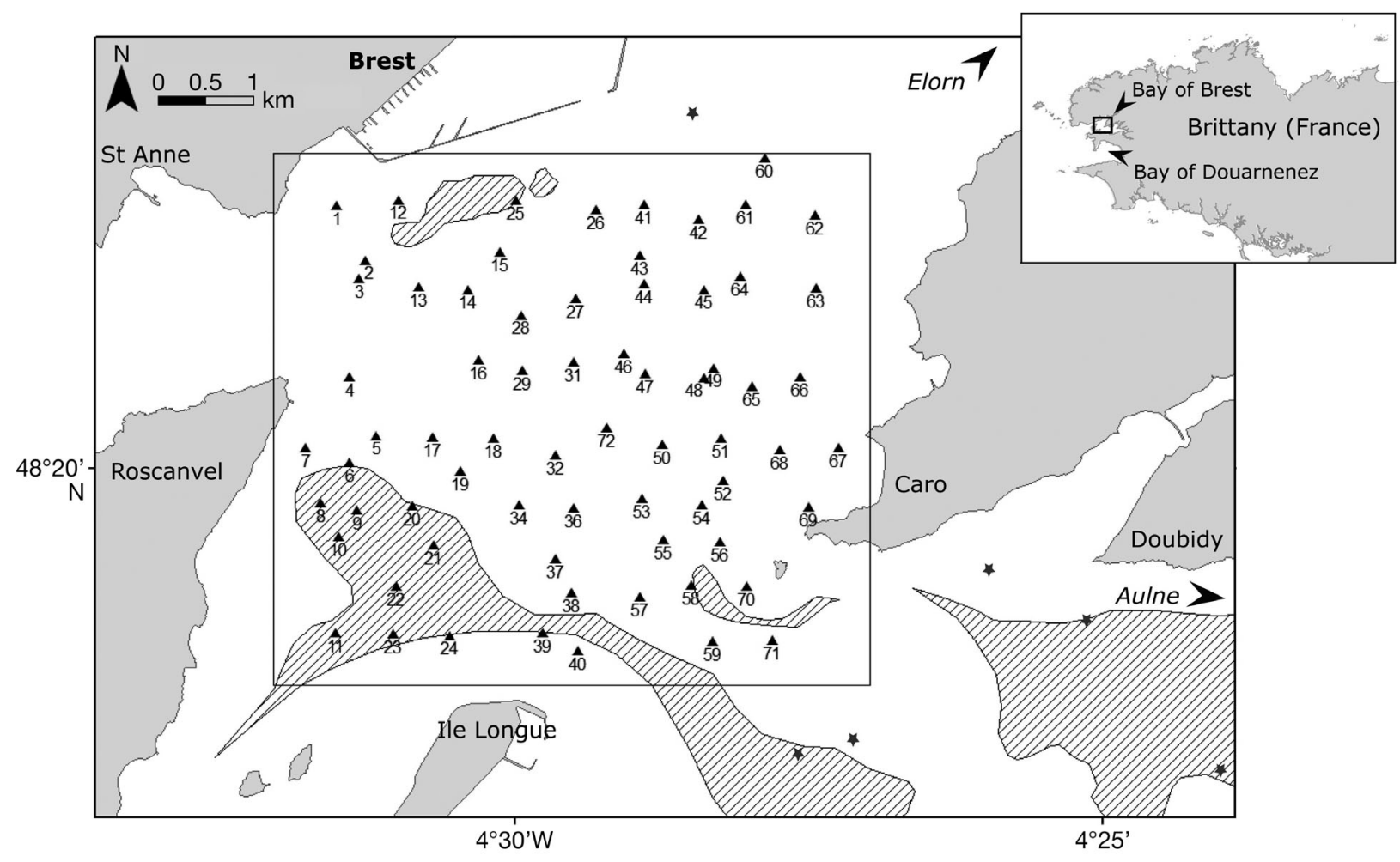

Fig. 1. The 72 sampling stations ( $\mathbf{\Delta})$ from the 1987 and 2011 benthic surveys covering the main central basin of the Bay of Brest, Brittany (France). Square: sampling area. $\star$ : additional stations prospected in 2011 (not included in data analysis). Hatched area: distribution of slipper limpet Crepidula fornicata in 1995 (modified after Chauvaud et al. 1998)

$\sim 50 \mathrm{~m}$, with a total cover of $1 \mathrm{~m}^{2}$. All HD pictures were georeferenced and used to estimate the individual numbers of Ophiocomina nigra and Ophiothrix fragilis.

We retrieved published densities of Ophiothrix fragilis from 1987 (Hily 1991) and added a new set of unpublished density data of Ophiocomina nigra from that same video survey, in order to compare both 1987 and 2011 surveys. The sampling occurred in May and February for 1987 and 2011 surveys, respectively. Even if sampling seasons were different, all the specimens sampled by video were $>5 \mathrm{~mm}$. A few complementary observations (not used in the 1987 and 2011 surveys comparison) were recorded towards the Aulne and the Elorn estuaries as well as in the westernmost part of the bay, toward the open ocean (Fig. 1).

To calculate the biomass (organic matter) for the whole prospected area for the 2 species, we used the ophiuroid densities from the 1987 and the 2011 surveys. A 2 step process required (1) to measure disc diameters of the ophiuroids from the 2011 survey and link mean diameter and density at each station, and (2) to establish a relationship between individual biomass and disc diameter:
(1) External disc diameters were measured to the closest millimeter with the scale provided by the laser pointer on the HD pictures. To avoid a measure bias, the measure was considered valid when individuals were well-flattened on the bottom. For each species, the disc diameters of 30 individuals were randomly measured among the $20 \mathrm{HD}$ pictures within each station. To strengthen our approach, additional HD pictures were taken from closed areas (Bay of Douarnenez) during the same 2011 survey (Fig. 1). The minimum size of specimens measured by laser pointer was $\sim 5 \mathrm{~mm}$ disc diameter for both species. All measurements were used to fit a general model of size vs. density.

(2) Additional samples of the 2 ophiuroid species were taken by scuba divers close to the studied area (Bay of Douarnenez) and brought to the laboratory for further analysis. The external disc diameter of all individuals ( $\mathrm{n}=183$ for Ophiothrix fragilis and $\mathrm{n}=196$ for Ophiocomina nigra) covering all size-classes of the population were measured to the closest millimeter. Echinoderms were then ashed in a muffle furnace at $550^{\circ} \mathrm{C}$ for $4 \mathrm{~h}$. The ash mass was subtracted from the dry mass to obtain the ash-free dry mass (mass; $\mathrm{mg}$ ) for each individual (see 'Data analysis'). 


\section{Data analysis}

Comparisons were made between past (1987) and current (2011) interpolated distributions and total biomasses of both Ophiocomina nigra and Ophiothrix fragilis from the 72 sampling stations. The 4 interpolations ( 2 dates $\times 2$ species) were performed using ordinary kriging, a geostatistical method that analyzes the spatial structure of the dataset through semi-variograms to estimate the best interpolation parameters (Kitanidis 1997). Semi-variograms were fitted with a theoretical exponential model (Matheron 1971), for each species separately. Densities (ind. $\mathrm{m}^{-2}$ ) were interpolated for a regular point grid covering the study area, with the kriging accounting for a minimum of 3 stations to a distance of $1 \mathrm{~km}$ from the grid point.

The disc diameter (diam) vs. density (dens) relationship was estimated from the stations estimates for Ophiocomina nigra and Ophiothrix fragilis separately as follows:

$$
\operatorname{diam}=a_{1} \times \log (\text { dens })+b_{1}
$$

where diam are the average disc diameters observed in each station and dens are the corresponding densities; $a_{1}$ and $b_{1}$ are species-specific constants. The coefficients of variations (i.e. standard deviation/ mean of disc diameter $\times 100$ ) were previously calculated for each station to test for the homogeneity in diameter within each station.

The ash-free dry mass (mass) vs. disc diameter (diam) relationship was estimated from individual observations for Ophiocomina nigra and Ophiothrix fragilis separately as follows:

$$
\log (\operatorname{mass})=a_{2} \times \operatorname{diam}+b_{2}
$$

where $a_{2}$ and $b_{2}$ are species-specific constants.

Combination of Eqs. (1) and (2) allowed estimating the average individual ash-free dry mass from station densities as follows:

$$
\log (\text { mass })=a_{3} \times \log (\text { dens })+b_{3}
$$

with $a_{3}=a_{1} \times a_{2}$ and $b_{3}=b_{1} \times a_{2}+b_{2}$.

For each grid point, biomass per square meter was calculated from kriged densities $\left(\right.$ dens $\left._{k}\right)$ by multiplying the average individual mass (mass, Eq.[3]) with the number of individuals per square meter (i.e. dens $_{k}$ ) as follows:

$$
\text { Biomass }=\exp \left[a_{3} \times \log \left(\text { dens }_{k}\right)+b_{3}\right] \times \text { dens }_{k}
$$

The total biomass of the studied area $\left(27 \mathrm{~km}^{2}\right)$ was summed from grid biomass Eq. (4) for each species and each survey. Eqs. (1) \& (2) could not be estimated from the 1987 survey as individual diameters and ash-free dry mass were not recorded. Estimators of the 2011 survey (i.e. $a_{3}$ and $b_{3}$ ) were thus used to estimate the 1987 biomasses from kriged densities.

Models and maps were performed with the R-software (R Development Core Team 2012); the 'gstat' library was used for estimating the parameters of the semi-variogram and for kriging.

\section{Seasonality index}

A seasonality index was used as a proxy to estimate the grazing pressure of suspension-feeding compartment in the ecosystem (Chauvaud et al. 2000). The seasonality index $(\alpha)$ is defined as $\alpha=260-\beta$, where $\beta$ is the number of days required to obtain half of the integrated chl a biomass (Berger \& Wefer 1990). We retrieved published data (from 1977 to 1996) of seasonality index $(\alpha)$ assessed over $260 \mathrm{~d}$ (from 15 February to 3 November) by Chauvaud et al. (2000), and built up the same seasonality index from 1999 to 2011. The integrated chl a biomass was estimated from surface-water chl a concentrations collected using data from the Bay of Brest buoy operated by the Service d'Observation en Milieu Littoral, INSUCNRS, Brest (http://somlit.epoc.u-bordeaux1.fr/; SOMLIT NATIONAL 2005).

\section{RESULTS}

\section{Distribution and density}

Deep changes were observed in the distribution of the 2 ophiuroid species between 1987 and 2011 (Fig. 2). Data from 1987 showed that Ophiocomina nigra was distributed in several patches in the central and in the north-easternmost parts of the study area. The largest patch was located in the central part and reached maximum densities between 150 and 500 ind. $\mathrm{m}^{-2}$ (Fig. 2). The interpolations revealed a 5 -fold increase in total $O$. nigra densities, between $1987(1.7 \times$ $10^{9}$ ind. for $\left.27 \mathrm{~km}^{-2}\right)$ and $2011\left(8.6 \times 10^{9}\right.$ ind. for $27 \mathrm{~km}^{-2}$ ), and reached densities of up and 1500 ind. $\mathrm{m}^{-2}$. The population distribution pattern remained very similar to 1987 (Fig. 2a) but showed that high density levels of between 150 to 500 ind. $\mathrm{m}^{-2}$ extended over almost all the study area (Fig. 2b). In 1987, distribution of Ophiothrix fragilis showed a similar pattern of distribution, with a central patch reaching maximum densities of between 500 and 1000 ind. $\mathrm{m}^{-2}$ (Fig. 2c). The distribution of $O$. fragilis 

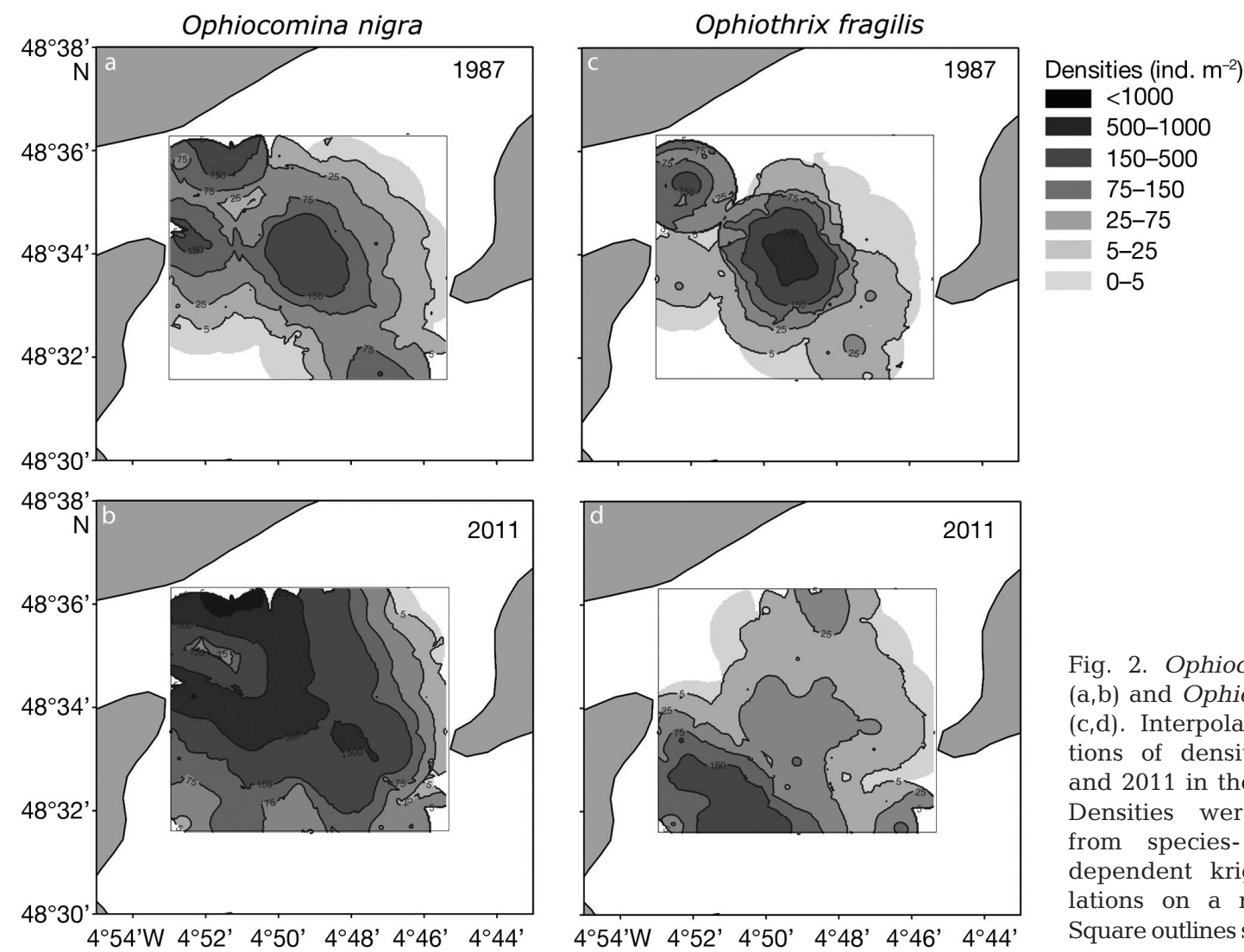

Fig. 2. Ophiocomina nigra $(\mathrm{a}, \mathrm{b})$ and Ophiothrix fragilis $(\mathrm{c}, \mathrm{d})$. Interpolated distributions of densities in 1987 and 2011 in the study area. Densities were estimated from species- and yeardependent kriged interpolations on a regular grid. Square outlines sampling area

drastically changed between 1987 and 2011: total densities decreased by $\sim 30 \%$ (from $1.7 \times 10^{9}$ to $1.2 \times$ $10^{9}$ ind. for $27 \mathrm{~km}^{-2}$ ) in the study area, and up to $90 \%$ in the central patch of the study area, which highlighted a local shift between ophiuroids. Individuals are now concentrated towards the southernmost part of the study area with the highest densities $>400$ ind. $\mathrm{m}^{-2}$ (Fig. 2d). The spatial distributions of $O$. nigra and $O$. fragilis revealed an important change over $25 \mathrm{yr}$, with both species having a complementary distribution in space. The high density area of $O$. fragilis seems now to be overlapping the slipper limpet Crepidula fornicata beds (shaded contours in Fig. 1). The HD videos revealed that these $C$. fornicata beds mainly consisted of dead shells in this area.

For the 2 species, coefficients of variation were calculated from disc measurements (2011 HD pictures) and showed a mean $( \pm \mathrm{SD}$ ) of $17 \pm 5 \%$ and $20 \pm 7 \%$ respectively for Ophiocomina nigra and Ophiothrix fragilis, hence supporting a relative homogenous size structure within each station. The relationship between mean diameter and density (Eq. 1) was significantly negative for Ophiocomina nigra $\left(\mathrm{R}^{2}=0.58\right.$ with $\mathrm{p}<0.001 ; \mathrm{n}=101$, Table 1) and Ophiothrix. fragilis $\left(\mathrm{R}^{2}=0.73\right.$ with $\mathrm{p}<0.001 ; \mathrm{n}=15$, Table 1$)$. For both species, these models showed that the higher the density, the smaller the specimens (Fig. 3).

Few observations also showed high densities of O. nigra (>1500 ind. $\mathrm{m}^{-2}$ ) beyond the sampling area, especially in the narrow opening channel, often on rocky area and gravel sediments. Mixed O. nigra and $O$. fragilis beds were also observed in stations towards the Aulne estuary, where densities of $>150$ ind. $\mathrm{m}^{-2}$ were calculated (Fig. 1)

Table 1. Estimated parameters of the relationships between individual diameter (diam), station densities (dens) or individual ash-free dry mass (mass) of Eqs. (1-3)

\begin{tabular}{|c|c|c|}
\hline Parameters & $\begin{array}{c}\text { Ophiocomina } \\
\text { nigra }\end{array}$ & $\begin{array}{l}\text { Ophiothrix } \\
\text { fragilis }\end{array}$ \\
\hline \multicolumn{3}{|c|}{ Eq.(1) $\operatorname{diam}=a_{1} \times \log (\operatorname{dens})+b_{1}$} \\
\hline$a_{1}$ & -1.55 & -2.06 \\
\hline$b_{1}$ & 18.83 & 19.50 \\
\hline \multicolumn{3}{|c|}{ Eq.(2) $\log ($ mass $)=a_{2} \times \operatorname{diam}+b_{2}$} \\
\hline$a_{2}$ & 0.22 & 0.25 \\
\hline$b_{2}$ & 2.18 & 3.03 \\
\hline \multicolumn{3}{|c|}{ Eq.(3) $\log ($ mass $)=a_{3} \times \log ($ dens $)+b_{3}$} \\
\hline$a_{3}=a_{1} \times a_{2}$ & -0.34 & -0.52 \\
\hline$b_{3}=b_{1} \times a_{2}+b_{2}$ & 6.26 & 7.90 \\
\hline
\end{tabular}




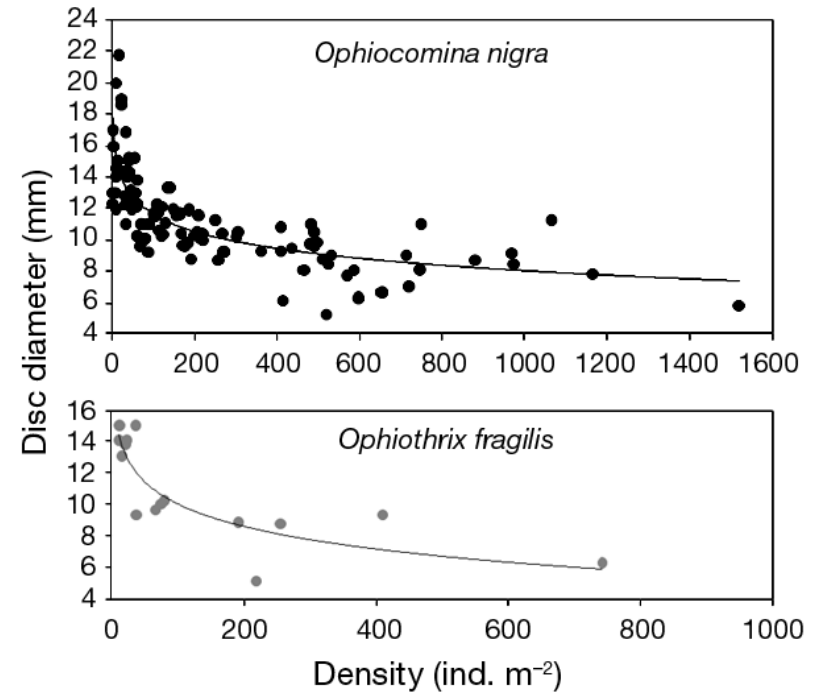

Fig. 3 Ophiocomina nigra and Ophiothrix fragilis. Relationships between mean disc diameter and density (ind. $\mathrm{m}^{-2}$ ) estimated from 2011 video pictures

\section{Biomass}

The relationships between size and biomass (organic matter, Eq. 2) were significantly positive for Ophiocomina nigra $\left(\mathrm{R}^{2}=0.84\right.$ with $\left.\mathrm{p}<0.001 ; \mathrm{n}=196\right)$ and Ophiothrix fragilis $\left(\mathrm{R}^{2}=0.70\right.$ with $\mathrm{p}<0.001 ; \mathrm{n}=$ 183) (Table 1, Fig. 4). The resulting relationships between density and biomass Eq. (4) were positive for O. nigra and O. fragilis (Fig. 5). The estimate of the total biomass in the study area showed that while the biomass of $O$. fragilis remained similar between 1987 and 2011 ( 360 t for $\left.27 \mathrm{~km}^{2}\right)$, O. nigra biomass increased 3-fold, ranging from <200 t in 1987 to 600 t ash-free dry mass in 2011 (Fig. 6).

\section{Seasonality index $(\alpha)$}

The seasonality index $(\alpha)$ decreased between 1980 and 1996, indicating that more days were needed to reach $50 \% \mathrm{chl}$ a biomass. The seasonality index estimated between 1999 and 2011 showed the exact opposite trend, with a decreasing number of days to reach $50 \%$ chl a biomass (Fig. 7).

\section{DISCUSSION}

\section{Changes in ophiuroid dominances}

Echinoderms play key ecological roles in ecosystems, where they often exhibit large population den-
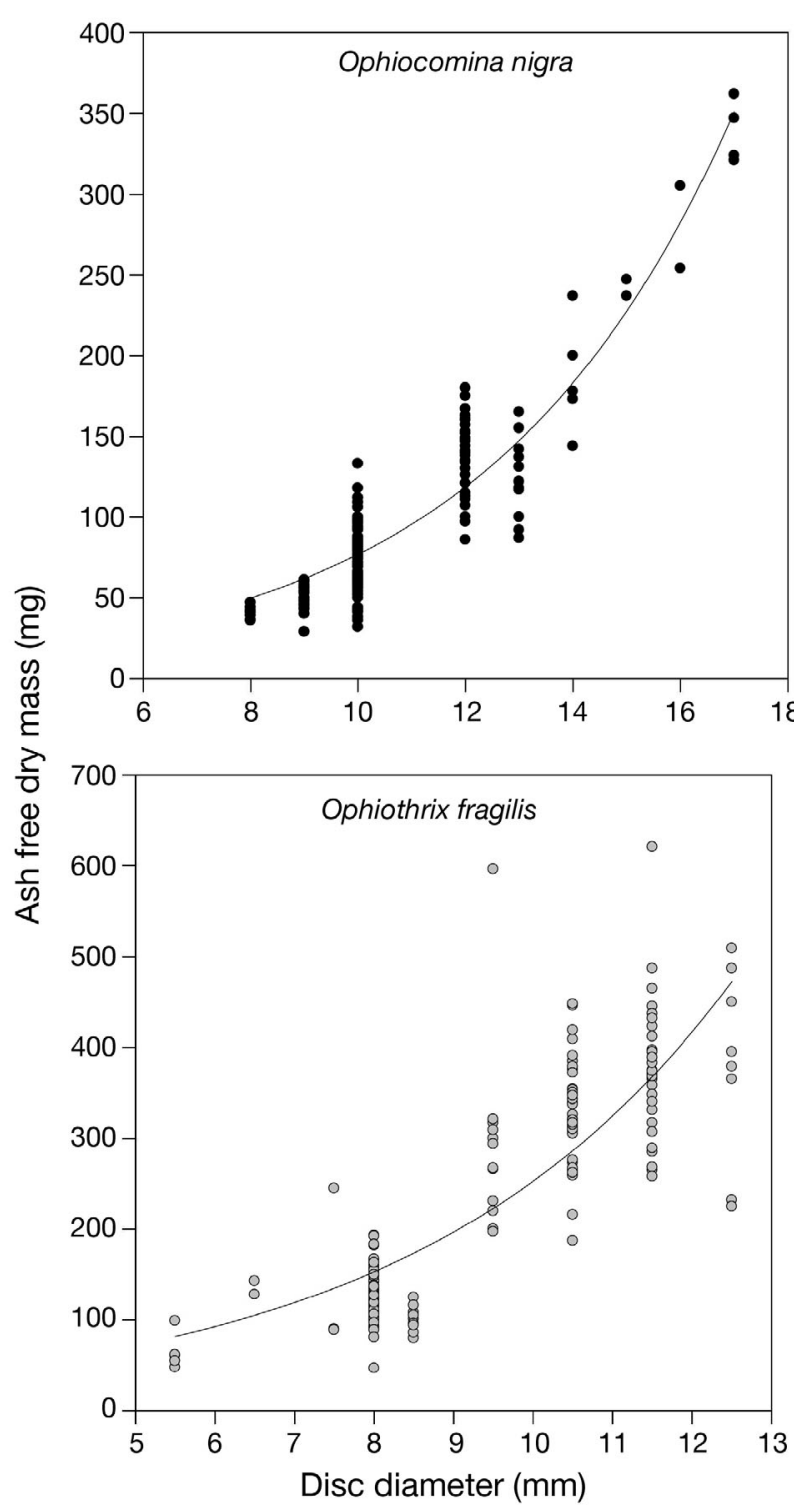

Fig. 4. Ophiocomina nigra and Ophiothrix fragilis. Relationships (Model 2) between the ash-free dry mass and the disc diameter. Model was fitted from all 2011 data pooled across the study site

sities (Uthicke et al. 2009). We focused on 2 very common ophiuroid species that occur in most European shallow coastal areas in a large variety of sedimentary features. The Bay of Brest was chosen to revisit the population status of Ophiothrix fragilis and Ophiocomina nigra, 2 very abundant species structuring the benthic compartment (Hily 1989, 1991). We used data collected 25 yr ago and conducted a survey with the same protocol to reveal multidecadal changes in the density and the biomass of the 2 ophiuroid species. The 2011 survey highlighted 


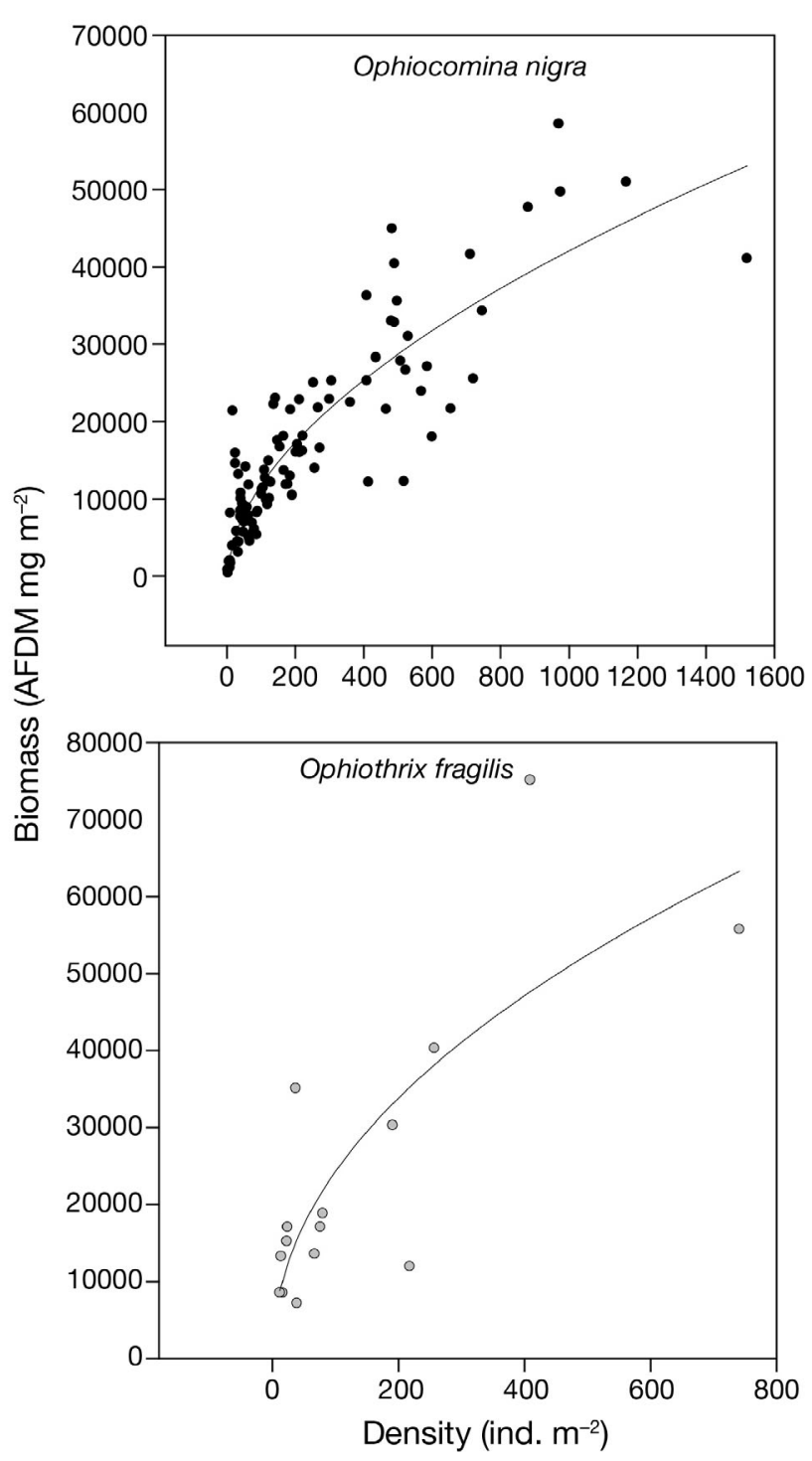

Fig. 5. Ophiocomina nigra and Ophiothrix fragilis. Relationships (Model 3) between the biomass (ash-free dry mass: AFDM) and the population density. Model was fitted from all 2011 data pooled across study site

that $O$. nigra had spread over and beyond the whole prospected area. Its densities were 5 times higher than the ones estimated for 1987: using the existing relationship between density and size, we showed that $O$. nigra biomass increased 3 -fold, reaching $22 \mathrm{t}$ $\mathrm{km}^{-2}$ (ash-free dry mass) in 2011. The O. fragilis population not only decreased in density but moved to the southernmost part of the study area. The total biomass of this species did not change between 1987 and 2011, and the 2011 distribution pattern revealed a clear exclusion of $O$. fragilis from the central part of the study area, where $O$. nigra is now highly dominant.

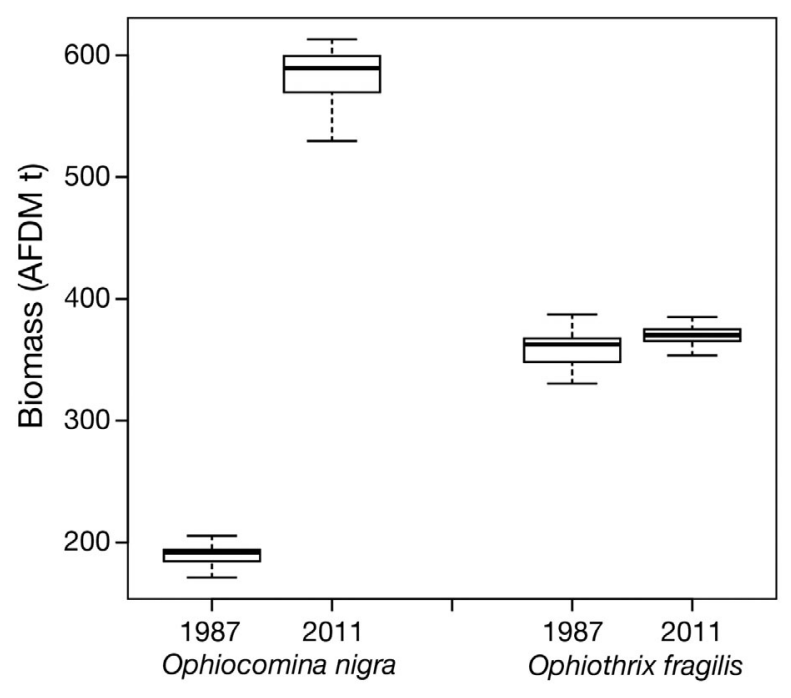

Fig. 6. Ophiocomina nigra and Ophiothrix fragilis. Boxplots estimates of total biomass (ash-free dry mass: AFDM, t) issued from species- and year-dependent kriged densities on a regular grid and density vs. biomass relationships (Model 4) in the study area. Horizontal line in box indicates the mean of the data, box and whiskers include 20 to $75 \%$ and $95 \%$ of the data, respectively

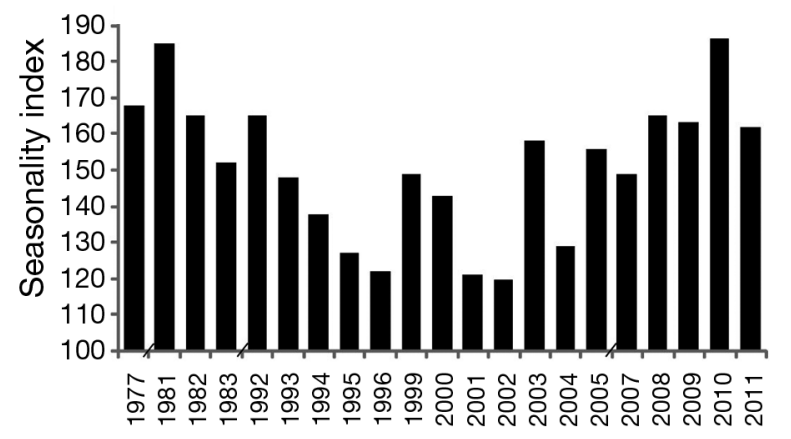

Fig. 7. Variation in the seasonality index $\alpha=260-\beta$, where $\beta$ is the number of days required to obtain half the integrated chl a biomass assessed over $260 \mathrm{~d}$ (from 15 February to 3 November), as calculated in Chauvaud et al. (2000, from 1977 to 1996) and in the present study (from 1999 to 2011), using data from the Bay of Brest buoy operated by the Service d'Observation en Milieu Littoral, INSU-CNRS, Brest (http://somlit.epoc.u-bordeaux1.fr/; @ SOMLIT NATIONAL 2005) since 1997

To our knowledge, this study reported for the first time such an increase in density for Ophiocomina nigra. Mixed Ophiothrix fragilis and O. nigra beds are a common feature in a variety of sediments in Europe, but are usually largely dominated by O. fragilis (e.g. Allain 1974, Vevers 1952, Cabioch 1967, Hughes 1998). While $O$. fragilis densities can peak with $>5000$ ind. $\mathrm{m}^{-2}$ (Davoult \& Migné 2001, Méar et 
al. 2006) because of its gregarious and social behavior (Broom 1975, Brun 1969), O. nigra is very rarely reported with high densities, especially when cooccurring with $O$. fragilis where it usually represents $<8 \%$ of the ophiuroid population (Holme 1984). Our maximum values (e.g. 1500 ind $\mathrm{m}^{-2}$ ) matched the only high density of $O$. nigra reported in the literature, in the west coast of Scotland, where this species locally reached 2000 ind. $\mathrm{m}^{-2}$ in a mono-specific bed (Aronson 1989). O. fragilis populations were reported to be stable over time (e.g. Holme 1984, Lefebvre et al. 2003), and the present investigation supports this population characteristic, when considering the total biomass of this species in the central Bay of Brest. In 1987, Hily (1991) reported the most dense O. fragilis beds in the central part of the study area in response to occurrence of optimal habitat features, such as suitable substrata, favorable local hydrodynamic conditions, and a high primary production. Our video survey showed that this species was now mainly reported in close association with dead slipper limpet Crepidula fornicata beds.

Echinoderms have previously been identified as a 'boom-bust' phylum, because of notoriously large changes in population density, but most echinoderm models refer to Asteroidea or Echinoidea families (see review by Uthicke et al. 2009). In our study, a 5-fold increase in Ophiocomina nigra density fits the definition of a large population density variation (at least doubling in population density), also called outbreaks, as defined by Uthicke et al. (2009). While it is difficult without time series to estimate the level and the tendency of deep changes in ophiuroid population, the present investigation targeted adults of well-known species with a long lifespan (up to $14 \mathrm{yr}$, as suggested by Gorzula 1977). Similar changes were observed in several embayments (e.g. in the Bay of Douarnenez). Observed changes in population densities were then not local episodic 'boom-bust' events but were very likely due to progressive changes in environmental conditions and/or anthropogenic factors.

\section{Ophiuroid success linked with human-induced environmental changes}

In most cases, fluctuations in high density populations are reported for echinoderms with planktotrophic larval development (Uthicke et al. 2009, Valentine \& Edgar 2010). Both Ophiocomina nigra and Ophiothrix fragilis are planktotrophic developers (Stöhr 2005), hence supporting the possibility of 2 outbreaking ophiuroids. Because the 2 species exhibit similar planktotrophic developments, large population density variations in 1 of the 2 species are most likely triggered by the association of biological traits or changes in food supply of adults.

While both adult ophiuroid species are reported to be suspension-feeders, collecting particles from the water-column with their arms (Aronson 1989), Ophiocomina nigra exhibits a much wider trophic plasticity and displays a very important versatile feeding behavior (Fontaine 1965), as this species is more mobile at the sediment-water interface and commonly behaves either as a deposit-feeder feeding from the surface film (Magnus 1963), browses from a variety of deposited material (Vevers 1956), or behaves as a carnivorous species, foraging over detritus or carrions (Nagabhushanam \& Colman 1959). As demonstrated for other echinoderms (Norkko et al. 2007, Thrush \& Cummings 2011), flexibility in feeding habits of $O$. nigra contributes to the success of this species (Fontaine 1965).

Changes in potential food supply in the Bay of Brest has probably resulted in an increase in Ophiocomina nigra density and enhanced the fecundity and fertilization success of adults, as demonstrated for other echinoderms (Sewell \& Levitan, 1992). For the last decade, green tides and high production of green macrophytes Ulva sp. have been an increasing issue in Brittany coastal waters (Dion \& Le Bozec 1996, Merceron et al. 2007). The Bay of Brest as well as many other embayments (inshore fringes and estuaries) exhibits frequent macroalgae blooms (Ménesguen et al. 2006), hence providing a large supply of macroalgae detritus for species which may benefit from this. Overall, O. nigra and Ophiothrix fragilis are widespread and abundant in many embayments in Brittany, especially southward in the Bay of Douarnenez (also impacted by green macroalgal blooms) where $O$. nigra also sharply increased during several decades (M. Guillou \& A. BlanchetAugriny unpubl. data).

Simultaneously, rocky western coasts of France (including the Bay of Brest) have been heavily colonized by wild oysters Crassostrea gigas in the last decade (Cognie et al. 2006). Lejart \& Hily (2011) investigated the consequences for the Bay of Brest and reported that mass biodeposits from the invasive oyster reefs were washed away from the reefs and sedimented in deeper areas of the bay. Such organically rich inputs could result in a diversified and unusual deposit-feeder fauna (Hily 1991, Lejart \& Hily 2011). Because of its higher trophic plasticity, Ophiocomina nigra benefited more from those changes than Ophiothrix fragilis. 
Anthropogenic disturbances in the Bay of Brest could also have induced changes in ophiuroid distribution. Dredging activities in this bay targeted the scallop Pecten maximus and more recently the warty clam Venus verrucosa. While the landing of scallops remained $<25 \mathrm{t} \mathrm{yr}^{-1}$ in 1980, it has linearly increased since then to reach $>350 \mathrm{t} \mathrm{yr}^{-1}$ in 2000 (Fleury et al. 2003). As demonstrated for the starfish Asterias rubens in the Barents Sea (Zolotarev 2002) or for the ophiuroid Ophiura albida (Gaspar et al. 2003), chronic dredging activities attract mobile scavengers and predators (Kaiser \& Spencer 1994). In late 1980, a restocking and sea-ranching program was launched for scallop in the Bay of Brest (Alban \& Boncoeur, 2008). The main seeding area perfectly fits within our study area, in the central part of the bay. This seeding program and the ultimately linked dredging activities very likely benefited Ophiocomina nigra, which is reported to feed on damaged or weak scallops (Jenkins et al. 2004). Over long-term periods, this could partly explain the success of $O$. nigra.

\section{Ecological consequences of changes in ophiuroid densities}

Changes in Echinoidea population densities can have deep consequences in the functioning of the ecosystem, as highlighted in the die-off of the tropical herbivore urchin Diadema antillarum, which transformed the coral community into a macroalgal community (Lessios 1988) or in the outbreak of urchin populations adversely affecting the kelp forest dynamic (Steneck et al. 2004). The Bay of Brest is a system where primary production and phytoplankton bloom events are partly regulated by suspensionfeeders (Grall \& Chauvaud 2002), and where large populations of the invasive slipper limpet Crepidula fornicata or the ophiuroid Ophiothrix fragilis dominate the benthic suspension-feeding compartment (Hily 1991, Chauvaud et al. 2000, Grall \& Chauvaud 2002). In addition to a spatial shift of the population, our video survey revealed that the $O$. fragilis had now colonized C. fornicata beds and that this area was the only one left uncolonized by Ophiocomina nigra in high densities. In the studied area, video filming revealed that the vast majority, if not all, slipper limpets were dead. We suggest here that the $O$. fragilis beds covering the $C$. fornicata beds had progressively lead to the death of most of the slipper limpets underneath. Whether $O$. fragilis caused the death of $C$. fornicata or not, dead shell beds are a very suitable habitat for $O$. fragilis which commonly live in more or less muddy microhabitats among shell and gravels (Cabioch 1967 , Warner \& Woodley 1975, Hily et al. 1988). Hence, the present study showed that $O$. nigra has excluded $O$. fragilis from the central part of the bay, leaving dead slipper limpet beds as potential habitat for $O$. fragilis and limiting this invasive gastropod's distribution in the central part of the Bay of Brest.

The first and probably the main consequence of ecological effect of changes in ophiuroid populations in this bay is that the Crepidula fornicata beds may no longer have the same grazing impact on the microalgae (phytoplankton) biomass. Indeed, Chauvaud et al. (2000) clearly demonstrated that the seasonality index was decreasing between 1980 and 1996 while the density and biomass of suspensionfeeders (and mostly the invasive $C$. fornicata) increased, indicating that the suspension-feeders were controlling the phytoplankton biomass. The opposite trend was observed between 1999 and 2011 (Fig. 7), which indicates that suspension-feeders were probably no longer having the same controlling effect on the phytoplankton blooms in the Bay of Brest.

Ophiuroid beds are known to play an important role in the fluxes of organic matter from the pelagic to the benthic system (Davoult et al. 1991). Sediment reworking through ophiuroid bioturbation also contributes to sediment biochemical processes (Lohrer et al. 2004, Webb \& Eyre 2004, McLenaghan et al. 2011). Because of its high densities and its mobility and burrowing activity within the superficial sediment layers, Ophiocomina nigra is likely to locally affect nutrient cycling at the sediment surface and ultimately modify the associated benthic assemblages. Ultimately, spreading of ophiuroid species over large areas may affect the habitat diversity. This assumption is supported by several studies and theoretical concepts in biology and ecology suggesting that the replacement of specialist by generalist species, such as O. nigra, with a change in functional attributes, is causing functional homogenization at the community level (Thrush et al. 2006, Clavel et al. 2010). Moreover, because of its non-exploitation by humans or predators, $O$. nigra could be considered as a trophic impasse and may decrease the efficiency of overall food web interactions in the ecosystem, as previously showed for Crepidula fornicata in other shallow-water systems (Arbach Leloup et al. 2008, Cugier et al. 2010).

Acknowledgements. This work was funded by the Programme National sur l'Environnement Côtier (PNEC) and by the Parc Naturel Marin d'Iroise (PNMI). The authors thank X. Caisey and B. Segalen for the video maintenance in 
steady optimal conditions, as well as J. D. Gaffet, F. Dérian, Dr. A. Carlier, and E. Amice for collecting echinoderms during the 'EDO' campaign. We thank C. Cordier and C. Croguennec for their help in producing maps. Dr. J. Grall (University of Brest) provided useful comments on an early draft of this manuscript.

\section{LITERATURE CITED}

Alban F, Boncoeur J (2008) Sea ranching and self-management in the Bay of Brest (France): technical change and institutional adaptation of a scallop fishery In: Townsend $\mathrm{R}$, Shotton $\mathrm{R}$ (eds) Case studies in fisheries selfgovernance. FAO Fisheries Technical Papers no. 504. FAO, Rome, p 41-52

Allain JY (1974) Ecologie des bancs d'Ophiothrix fragilis (Abildgaard) (Echinodermata: Ophiuroidea) dans le golfe Normanno-Breton. Cah Biol Mar 15:235-273

Allen JR (1998) Suspension feeding in the brittle-star Ophiothrix fragilis: efficiency of particle retention and implications for the use of encounter-rate models. Mar Biol 132: 383-390

Andrew NL, Underwood AJ (1992) Associations and abundance of sea urchins and abalone on shallow subtidal reefs in southern New South Wales. Aust J Mar Freshw Res 43:1547-1559

- Arbach Leloup F, Desroy N, Le Mao P, Pauli D, Le Pape O (2008) Interactions between a natural food web, shellfish farming and exotic species: the case of the Bay of Mont Saint Michel (France). Estuar Coast Shelf Sci 76:111-120

Aronson RB (1989) Brittlestar beds: low-predation anachronisms in the British Isles. Ecology 70:856-865

Berger WH, Wefer G (1990) Export production: seasonality and intermittency, and paleoceanographic implications. Palaeogeogr Palaeoclimatol Palaeoecol 89:245-254

Bourgoin A, Guillou M (1988) Demographic study of Amphiura filiformis (Echinodermata: Ophiuroidea) in Concarneau Bay (Finistère, France). Oceanol Acta 11: 79-87

$>$ Bowner T (1982) Reproduction in Amphiura filiformis (Echinodermata: Ophiuroidea): seasonality in gonad development. Mar Biol 69:281-290

Broom DM (1975) Aggregation behavior of the brittle-star Ophiothrix fragilis. J Mar Biol Assoc UK 55:191-197

Brun E (1969) Aggregation of Ophiothrix fragilis (Abildgaard) (Echinodermata: Ophiuroidea). Nytt Mag Zool 17: $155-60$

Cabioch L (1967) Résultats obtenus par l'emploi de la photographie sous marine sur le fonds du large de Roscoff. Helgol Wiss Meeresunters 15:361-70

Chardy P, Guennegan Y, Branellec J (1980) Photographie sous-marine et analyse des peuplements benthiques essays en rade de Brest. CNEXO Scientific and Technical Publications no. 41. Centre National pour l'Exploitation des Océans, Brest

Chauvaud L, Thouzeau G, Paulet YM (1998) Effects of environmental factors on the daily growth rate of Pecten maximus juveniles in the Bay of Brest (France). J Exp Mar Biol Ecol 227:83-111

Chauvaud L, Jean F, Ragueneau O, Thouzeau G (2000) Long-term variation of the Bay of Brest ecosystem: benthic-pelagic coupling revisited. Mar Ecol Prog Ser 200: $35-48$

Clavel J, Julliard R, Devictor V (2010) Worldwide decline of specialist species: toward a global functional homogenization? Front Ecol Environ 9:222-228

Cognie B, Haure J, Barille L (2006) Spatial distribution in a temperate coastal ecosystem of the wild stock of the farmed oyster Crassostrea gigas (Thunberg). Aquaculture 259:249-259

Coum A (1979) La population de crépidules Crepidula fornicata (L.) en rade de Brest: écologie et dynamique. Thèse de doctorat, Université Bretagne Occidentale, Brest

> Cugier P, Struski C, Blanchard M, Mazurié J and others (2010) Assessing the role of benthic filter feeders on phytoplankton production in a shellfish farming site: Mont Saint Michel Bay, France. J Mar Syst 82:21-34

- Dauvin JC, Ruellet T (2008) Macrozoobenthic biomass in the Bay of Seine (eastern English Channel). J Sea Res 59: 320-326

Davoult D, Migné A (2001) Respiration and excretion of a dense Ophiothrix fragilis population in the Bay of Seine (English Channel, France). In: Barker M (ed) Echinoderm 2000. Swets \& Zeitlinger, Lisse, p 243-248

Davoult D, Gounin F, Janquin MA (1991) Ammonium excretion by the ophiurid Ophiothrix fragilis as a function of season and tide. Mar Biol 111:425-429

Dion P, Le Bozec S (1996) The French Atlantic coasts. In: Shramm W, Nienhuis PH (eds) Marine benthic vegetation. Recent changes and the effects of eutrophication. Springer-Verlag, Berlin, p 251-264

Fleury PG, Carval JP, Muzellec ML, Gérard A, Barret J, Cochard JC, Dao JC (2003) 1983-2002: The 20 year development of the King scallop (Pecten maximus) seafarming industry in the Bay of Brest (France). Historical record, results, prospect. Abstract for the 14th Pectinid Workshop, St. Petersburg (Florida, USA). http://archimer. ifremer.fr/doc/00000/7307/

Fontaine AR (1965) The feeding mechanisms of the Ophiuroid Ophiocomina nigra. J Mar Biol Assoc UK 45: 373-385

- Gaspar MB, Santos MN, Leitao F, Chicharo L, Chicharo A, Monteiro CC (2003) Recovery of substrates and macrobenthos after fishing trials with a new Portuguese clam dredge. J Mar Biol Assoc UK 83:713-717

Goransson P (2002) Petersen's benthic macrofauna stations revisited in the Oresund area (southern Sweden) and species composition in the 1990s - signs of decreased biological variation. Sarsia 87:263-280

Gorzula SJ (1977) A study of growth in the brittle star Ophiocomina nigra. West Nat 6:13-33

- Grall J, Chauvaud L (2002) Marine eutrophication and benthos: the need for new approaches and concepts. Glob Change Biol 8:813-830

Guillou M (1996) Biotic and abiotic interactions controlling starfish outbreaks in the Bay of Douarnenez, Brittany, France. Oceanol Acta 19:415-420

Hily C (1989) La mégafaune benthique des fonds meubles de la rade de Brest: pré-échantillonnage par vidéo sousmarine. Cah Biol Mar 30:433-454

Hily C (1991) Is the activity of benthic suspension feeders a factor controlling water quality in the Bay of Brest? Mar Ecol Prog Ser 69:179-188

Hily C, Girardeau JP, Quéguiner B (1988) Rythme tidal d'activité trophique d'Ophiothrix fragilis en rade de Brest. C R Acad Sci Paris 307:265-270

> Hily C, Le Loc'h F, Grall J, Glémarec M (2008) Soft bottom macrobenthic communities of North Biscay revisited: long term evolution under fisheries-climate forcing. 
Estuar Coast Shelf Sci 78:413-425

$>$ Holme NA (1984) Fluctuations of Ophiothrix fragilis in the western English Channel. J Mar Biol Assoc UK 64: 351-378

> Houk P, Raubani J (2010) Acanthaster planci outbreaks in Vanuatu coincide with ocean productivity, furthering trends throughout the Pacific Ocean. J Oceanogr 66: $435-438$

> Hughes TP (1994) Catastrophes, phase shifts, and largescale degradation of a Caribbean coral reef. Science 265: 1547-1551

Hughes DJ (1998) Subtidal brittlestar beds: an overview of dynamics and sensitivity characteristics for conservation management of marine SACs. Prepared for Scottish Association for Marine Science (SAMS) for the UK Marine SACs Project

> Jenkins SR, Mullen C, Brand AR (2004) Predator and scavenger aggregation to discarded by-catch from dredge fisheries: importance of damage level. J Sea Res 51: 69-76

Kaiser MJ, Spencer BE (1994) Fish scavenging behavior in recently trawled areas. Mar Ecol Prog Ser 112:41-49

Kitanidis P (1997) Introduction to geostatistics: application to hydrology. Cambridge University Press, Cambridge

Le Pape O, Del Amo Y, Cann P, Ménesguen A, Aminot A, Quéguiner B, Tréguer P (1996) Resistance of a coastal ecosystem under increasing eutrophic conditions: the Bay of Brest (France), a semi-enclosed zone of western Europe. Cont Shelf Res 16:1885-1907

Lefebvre A, Ellien C, Davoult D, Thiébaut E, Salomon JC (2003) Pelagic dispersal of the brittle star Ophiothrix fragilis larvae in a megatidal area (English Channel, France) examined using an advection/diffusion model. Estuar Coast Shelf Sci 57:421-433

Lejart M, Hily C (2011) Differential response of benthic macrofauna to the formation of novel oyster reefs (Crassostrea gigas, Thunberg) on soft and rocky substrate in the intertidal of the Bay of Brest, France. J Sea Res 65: 84-93

> Lessios HA (1988) Population-dynamics of Diadema antillarum (Echinodermata, Echinoidea) following mass mortality in Panama. Mar Biol 99:515-526

Lohrer AM, Thrush SF, Gibbs MM (2004) Bioturbators enhance ecosystem function through complex biogeochemical interactions. Nature 431:1092-1095

Magnus DBE (1963) Über das Abweiden der Flutwasseroberfläche durch den Schlangenstern Ophiocoma scolopendrina (Lamarck). Zool Anz 26(Suppl):471-481

Matheron G (1971) The theory of regionalized variables and its applications. Cahiers du Centre de Morphologie Mathématique de Fontainebleu 5. École National Supérieure des Mines, Paris

> McLenaghan NA, Tyler AC, Mahl UH, Howarth RW, Marino RM (2011) Benthic macroinvertebrate functional diversity regulates nutrient and algal dynamics in a shallow estuary. Mar Ecol Prog Ser 426:171-184

Méar Y, Poizot E, Murat A, Lesueur P, Thomas M (2006) Fine-grained sediment spatial distribution on the basis of a geostatistical analysis: example of the eastern Bay of the Seine (France). Cont Shelf Res 26:2335-2351

> Ménesguen A, Cugier P, Leblond I (2006) A new numerical technique for tracking chemical species in a multisource, coastal ecosystem applied to nitrogen causing Ulva blooms in the Bay of Brest (France). Limnol Oceanogr 51: 591-601
Merceron M, Antoine V, Auby I, Morand P (2007) In situ growth potential of the subtidal part of green tide forming Ulva spp. stocks. Sci Total Environ 384:293-305

Muths D, Jollivet D, Davoult D (2010) Population dynamics disparities of the common brittle-star Ophiothrix fragilis between three localities of the English Channel. In: Harris LG, Böttger A, Walker CW, Lesser MP (eds) Echinoderms: Durham. Proc 12th Int Echinoderm Conf, 7-11 Aug 2006, Durham, New Hampshire, USA. CRC Press, London, p 627-632

Nagabhushanam AK, Colman JS (1959) Carrion-eating by ophiuroids. Nature 184:285

Neumann H, Reiss H, Rakers S, Ehrich S, Kröncke I (2009) Temporal variability in southern North Sea epifauna communities after the cold winter of 1995/1996. J Mar Sci 66:2233-2243

> Norkko A, Thrush SF, Cummings VJ, Gibbs MM, Andrew NL, Norkko J, Schwarz AM (2007) Trophic structure of coastal Antarctic food webs associated with changes in sea ice and food supply. Ecology 88:2810-2820

R Development Core Team (2012) R: a language and environment for statistical computing. $\mathrm{R}$ Foundation for Statistical Computing, Vienna, Austria. www.R-project. org

Reise K (1982) Long-term changes in the macrobenthic invertebrate fauna of the Wadden Sea: Are polychates about to take over? Neth J Sea Res 16:29-36

Reise K, Schubert A (1987) Macrobenthic turnover in the subtidal Wadden Sea: the Norderaue revisited after 60 years. Helgol Mar Res 41:69-82

Sewell MA, Levitan DR (1992) Fertilization success during a natural spawning of the dendrochirote sea cucumber Cucumaria miniata. Bull Mar Sci 51:161-166

Seymour RM, Bradbury RH (1999) Lengthening reef recovery times from crown-of-thorns outbreaks signal systemic degradation of the Great Barrier Reef. Mar Ecol Prog Ser 176:1-10

> Steneck RS, Vavrinec J, Leland AV (2004) Accelerating trophic-level dysfunction in kelp forest ecosystems of the Western North Atlantic. Ecosystems 7:323-332

Stöhr S (2005) Who's who among baby brittle stars (Echinodermata: Ophiuroidea): postmetamorphic development of some North Atlantic forms. Zool J Linn Soc 143: 543-576

> Thiébaut E, Cabioch L, Dauvin JC, Retière C, Gentil F (1997) Spatio-temproral persistence of the Abra alba-Pectinaria koreni muddy-fine sand community of the eastern Bay of Seine. J Mar Biol Assoc UK 77:1165-1185

Thrush SF, Cummings VJ (2011) Massive icebergs, alteration in primary food resources and change in benthic communities at Cape Evans, Antartica. Mar Ecol 32:289-299

Thrush SF, Gray JS, Hewitt JE, Ugland KI (2006) Predicting the effects of habitat homogenization on marine biodiversity. Ecol Appl 16:1636-1642

Uthicke S, Schaffelke B, Byrne M (2009) A boom-bust phylum? Ecological and evolutionary consequences of dense variations in echinoderms. Ecol Monogr 79:3-24

> Valentine JP, Edgar GJ (2010) Impact of a population outbreak of the urchin Tripneustes gratilla amongst Lord Howe Island coral communities. Coral Reefs 29: $399-410$

Vevers HG (1952) A photographic survey of certain areas of the sea floor near Plymouth. J Mar Biol Assoc UK 31: 215-222

Vevers HG (1956) Observations on feeding mechanisms in 
some ophiuroids. Proc Zool Soc Lond 126:484-485

> Warner GF, Woodley JD (1975) Suspension-feeding in the brittle star Ophiothrix fragilis. J Mar Biol Assoc UK 55: 199-210

> Webb AP, Eyre BD (2004) The effect of natural populations of the burrowing and grazing soldier crab (Mictyris longicarpus) on sediment irrigation, benthic metabolism and nitrogen fluxes. J Exp Mar Biol Ecol 309:1-19

Editorial responsibility: Hans-Heinrich Janssen, Oldendorf/Luhe, Germany
Wharton WG, Mann KH (1981) Relationship between destructive grazing by the sea urchin, Strongylocentrotus droebachiensis and the abundance of American lobster, Homarus americanus, on the Atlantic coast of Nova Scotia. Can J Fish Aquat Sci 38:1339-1349

Zolotarev P (2002) Population density and size structure of sea stars on beds of Iceland scallop, Chlamys islandica, in the southeastern Barents Sea. Sarsia 87:91-96

Submitted: February 13, 2012; Accepted: April 26, 2012

Proofs received from author(s): July 14, 2012 